\title{
Innovative nursing: green care farms for people with dementia
}

\section{Editorial}

Since I was a little girl I remember my grandma as a hard workingwoman. Her husband, my grandpa died when I wasn't even born. At 5:00 in the morning you would find grandma's bed empty. You would find her bend down in her huge garden where she had already planted peas and beans and carrots, now pulling onions and salads or digging potatoes. Regardless the weather she was working in her garden, or woods, or meadow, or taking care of animals. She had rabbits, goats, chickens, cats, and a dog. In the winter she was knitting, separating the beans from the chaff, husking corn, and of course telling stories to her grandchildren. In short her motto was: "work and pray". Now she is 89 years old lady, and she still likes to go out to the garden, and tries to work as much as she can, when she has a bad day, when she is tired, and in pain, she just sits outside and observes the garden.

Approximately 10 kilometers from her house is a nursing home. I must say it is very modern building. The owners always adapting something like building a place for daycare center, new terrace, and so on. However in my opinion the dining room is rather dark, and crowded, and without a view. I worked there a long time ago when I was a nursing student. I worked in closed ward for people with advanced stages of dementia. One-day occupational therapists asked me, if I can have a drawing hour with patients on the ward, to keep them busy. So I told them to draw something. But they weren't so pleased with this occupation, and even more, one older gentleman firmly said: "we are not in the kindergarten". I don't need to explain further, drawing hour clearly was a disaster. And to tell you the truth, I cannot even imagine asking my grandma to draw something; she would probably ask me if I went mad. The next day, after a lite bit of thinking I had another "to keep them busy hour", however I ask the patient to help me separating the beans from the chaff, which I have brought from my grandma's house. They were delighted to help me. So husking corn, knitting, watering the flowers became our daily routine, when I was in charge, and we were all pretty active and satisfied.

So despite the new modern building I just cannot picture my grandma to be happy and calm in this kind of environment, like the majority of people her age, who were used live in green surroundings, as many of them grew up on farms. Therefore I can quite easily picture my grandma living at the farm. People with dementia cannot adapt to the new environment, therefore we have to adapt new environment to them. And furthermore there is a stigma attached to going to a nursing home. For majority of old people this means the "final destination", where you go when you are a burden to your family and society.

This client group needs a trusted and recognizable living
Volume I Issue 2 - 2016

\author{
Barbara Pajk \\ University Psychiatric Clinic Ljubljana, Slovenia
}

Correspondence: Barbara Pajk, University Psychiatric Clinic Ljubljana, Slovenia, Email barby.pajk@gmail.com

Received: November 20, 2016 | Published: November 23, 2016

environment with a homely atmosphere. A care farm offers such an environment. Older people experience staying on a farm as a part of "normal" life. ${ }^{1}$ Engaging people with dementia in meaningful activities, that they were used to do when living at home, like preparing the meal, light cleaning tasks, feeding animals, gardening, dusting, walking, enjoying coffee together, and so on. Therefore living in a farm can bring a person with dementia increase sense of self-respect, dignity and confidence, and well-being.

Many older people with dementia leave the houses less frequently and thereby lose their social contacts. They can make new contacts in the farm. Program in the farm is tailored to suit the normal, familiar rhythm of the life of the older people. Older people on care farms are also more often outside in the open air. Older people on care farms feel stimulated to stay active and to do things together, like walking, ranking the leaves, feeding animals, or just watching, which helps them to maintain their physical condition. ${ }^{1}$

Even more the research conducted by De Bruin, ${ }^{2}$ found out that people with dementia included in a day care program on a care farm had a significantly higher fluid and food intake per day. So if you ask me, where I would like to have my meals when getting old? For sure somewhere outside, looking at the green nature, with a small dog in my lap.

Leading countries that provide day care on care farms include: Norway, the Netherlands, France, Italy, Belgium, Austria, the UK, Germany, and the Ireland. ${ }^{3}$ In the Netherlands, approximately 200 green care farms provide day care for people with dementia. ${ }^{2}$

\section{Acknowledgements}

None.

\section{Conflict of interest}

The author declares no conflict of interest. 